\title{
Examination of the recommended safe and unsafe zone for placement of surgical instruments in thoracentesis and video-assisted thoracic surgery: a cadaveric study
}

\author{
D. Solomon ${ }^{1}$, J. Sharp², D. Boydstun ${ }^{3}$, C. Persaud ${ }^{3}$, J. Pfeiffer ${ }^{3}$, A. Olinger ${ }^{4}$ \\ ${ }^{1}$ MSII Medical Student, Kansas City University of Medicine and Biosciences, Kansas City, MO, United States \\ ${ }^{2}$ MSIII Medical Student, Kansas City University of Medicine and Biosciences, Kansas City, MO, United States \\ ${ }^{3}$ Clinical Anatomy Fellow, Kansas City University of Medicine and Biosciences, Kansas City, MO, United States \\ ${ }^{4}$ Department of Anatomy, Kansas City University of Medicine and Biosciences, Kansas City, MO, United States
}

[Received: 23 September 2015; Accepted: 2 November 2015]

Background: Thoracentesis and video-assisted thoracic surgery procedures can result in haemorrhage as a consequence of severing the collateral branches of the posterior intercostal artery. These branches have been shown to be most common in the $5^{\text {th }}$ intercostal space (ICS). Tortuosity has been shown to be especially prevalent nearer to midline. A group of investigators have recommended the $4^{\text {th }}$ and $7^{\text {th }}$ ICS, $120 \mathrm{~mm}$ lateral to midline as a safe zone, least likely to hit branches when cutting into the ICS. The present study aimed to investigate that safe zone as a better entry points for procedures. In addition, investigation of the least safe $5^{\text {th }}$ ICS was also performed.

Materials and methods: A total of 56 embalmed human cadavers were selected for the study. With the cadavers laid prone, $2 \mathrm{~cm}$ incisions were made at the $4^{\text {th }}, 5^{\text {th }}$ and $7^{\text {th }}$ ICS, $120 \mathrm{~mm}$ lateral to midline bilaterally. The cadavers were then placed supine and the incisions were dissected. Careful attention was paid to identify if any collateral branches were cut.

Results: After thorough dissection of the $4^{\text {th }}, 5^{\text {th }}$ and $7^{\text {th }}$ ICS incision sites, it was shown that damage to the $5^{\text {th }}$ intercostal was seen most frequently.

Conclusions: Based on this cadaveric study, a $2 \mathrm{~cm}$ incision at the $4^{\text {th }}, 5^{\text {th }}$ and $7^{\text {th }}$ ICS $120 \mathrm{~mm}$ lateral from midline resulted in the most damage at the level of the $5^{\text {th }}$ ICS. The $4^{\text {th }}$ ICS had the least damage seen. Therefore, it is recommended

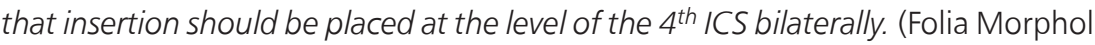
2016; 75, 2: 240-244)

Key words: posterior intercostal artery, intercostal anatomy, thoroscopy, thoracic surgery

\section{INTRODUCTION}

Thoroscopy and thoracentesis are well-established procedures currently in widespread use. While haemothorax is a relatively rare complication, it can be very serious when it occurs. The major cause of haemothorax in thoracentesis is laceration of the posterior intercostal artery or its collateral branches $[9,12]$. Reports of intercostal artery laceration

Address for correspondence: Dr D. Solomon, D.O., Kansas City University of Medicine and Biosciences, Kansas City, MO, United States, tel: 321-848-4986, e-mail: DanielleLSolomon@gmail.com 
and subsequent haemothorax have existed in the literature since 1970 [2], but at present there is no comprehensive description of the posterior intercostal and collateral vascular anatomy [3]. Another procedure gaining popularity among clinicians for resection of lung tumours is video-assisted thoracic surgery (VATS). Haemorrhaging secondary to trocar penetration of the chest wall is one the most common complications associated with VATS, and it may be severe $[5,6,9]$. One specific patient population at increased risk for haemothorax secondary to chest wall penetration are the elderly, as their posterior intercostal and collateral arteries are known to become more tortuous with advancing age, thereby decreasing safe access area within the intercostal space (ICS) [1, 12]. The current recommended approach to the thoracic cavity in thoracentesis is $5-10 \mathrm{~cm}$ lateral to the spine in the $3^{\text {rd }}-8^{\text {th }}$ ICSs [11]. In VATS, access to the thoracic cavity is achieved with trocars at three sites: 1 ) in the $7^{\text {th }}$ or $8^{\text {th }}$ ICS between the mid-axillary and posterior axillary line, 2) in the $5^{\text {th }}$ ICS at the anterior axillary line and 3 ) in the $5^{\text {th }}$ ICS $2 \mathrm{~cm}$ to $3 \mathrm{~cm}$ medial to the scapula [4]. Our previous work sought to establish the mean distance from palpable bony landmarks, the spinous processes of T3-T8, to the branch points of the collateral branch of the posterior intercostal artery, the branch point of additional collateral branches of the posterior intercostal artery and points of maximum tortuosity within the ICSs of T3-T8 [10]. It was determined that the $4^{\text {th }}$ and $7^{\text {th }}$ ICSs had few collateral branches traversing the ICSs. On the other hand, the $5^{\text {th }}$ ICS showed the most damage to the posterior intercostal vessels. Furthermore by making incisions thought the ICS $120 \mathrm{~mm}$ lateral to the midline the majority of vascular tortuosity could be avoided. Knowledge of the location of these variations should establish a surgical safe-zone for thoracic access using external landmarks that may be palpated intraoperatively, thereby decreasing the incidence of haemothorax in thoracentesis and VATS procedures.

The purpose of this study was to test the surgical unsafe and safe-zones established in our previous work by performing mock procedures and making incisions through the ICS in the prescribed safe-zone. Then to dissect the ICS and determine whether or not the posterior intercostal artery or any of the branches of the posterior intercostal artery were disrupted. Comparing the findings of the current study with the reported incidence of

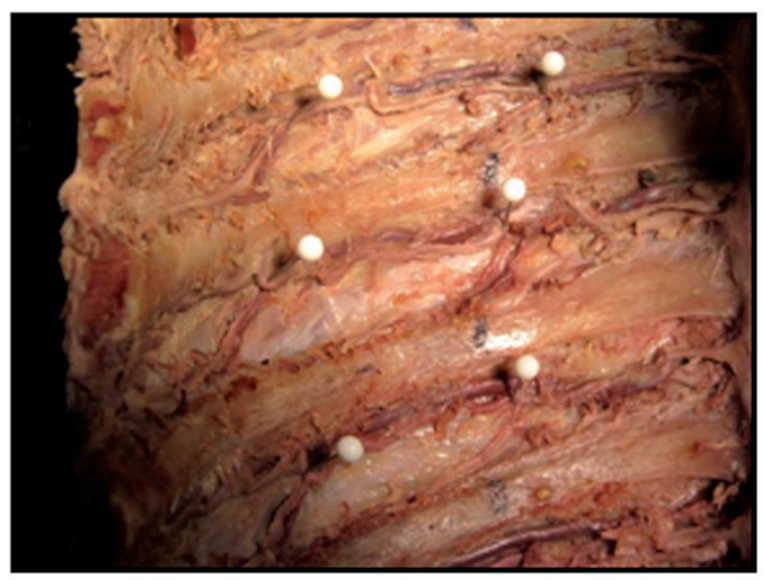

Figure 1. Multiple collateral branches from the posterior intercostal artery.

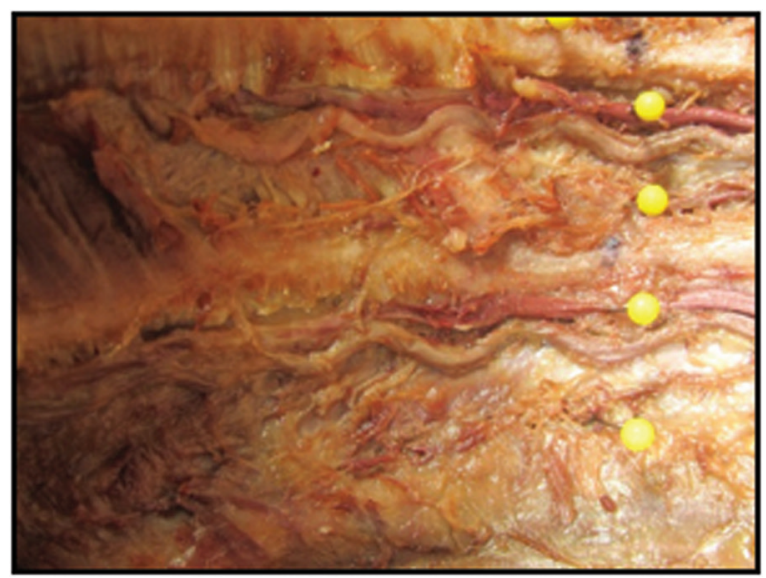

Figure 2. Example of tortuosity of the posterior intercostal artery occluding greater than $30 \%$ of the intercostal space.

haemothorax should determine whether or not the surgical safe-zone is, in fact, a safer access point through the thoracic wall (Fig. 1).

\section{MATERIALS AND METHODS}

A total of 56 embalmed human cadavers were evaluated in this study. With the cadaver in the supine position, the anterior thoracic wall was removed with cuts made bilaterally at the midaxillary line. The lungs and heart were removed as well as the parietal pleura of the posterior thoracic wall. With the cadavers in the prone position a $2 \mathrm{~cm}$ incision was made in the $4^{\text {th }}, 5^{\text {th }}$ and $7^{\text {th }} I C S$, at the midpoint between the superior and inferior rib, $120 \mathrm{~cm}$ from the midline. The incisions were performed by an investigator familiar with the procedure for insertion of a chest tube or camera for VATS. This procedure produced a total of 336 incisions to be 


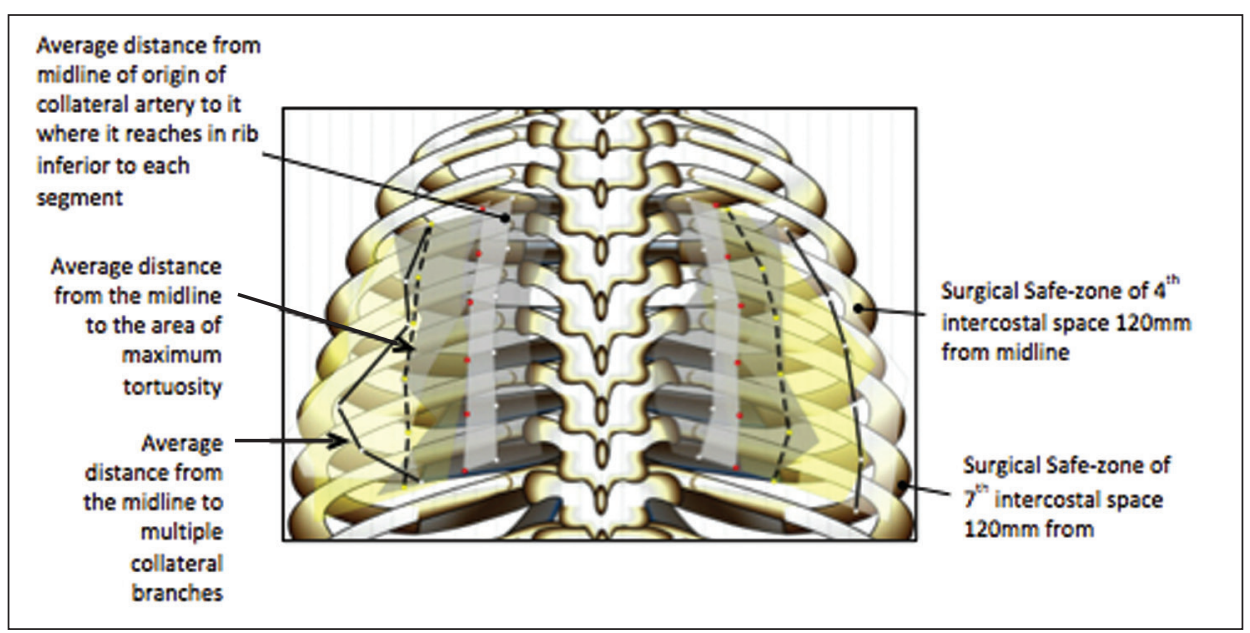

Figure 3. Project design.

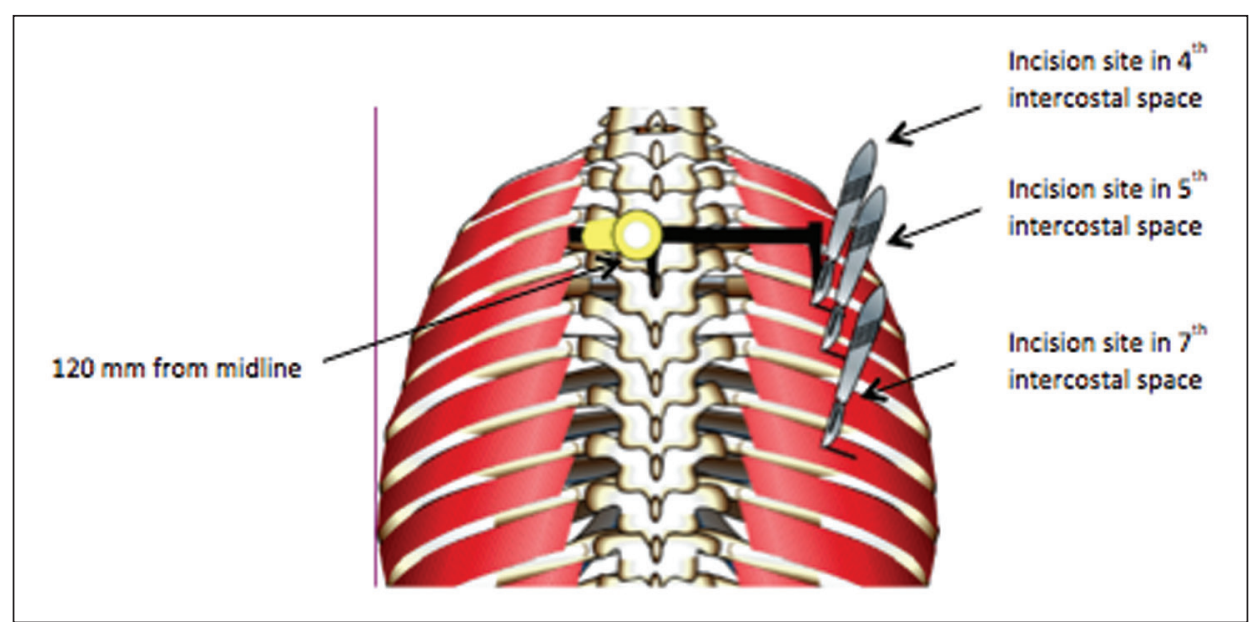

Figure 4. Schematic of incision locations.

evaluated. With the cadavers in the supine position the innermost intercostal muscles were carefully dissected to reveal the posterior intercostal artery and the collateral branches originating from that vessel. The arteries were carefully inspected to determine whether or not the incision made by the other investigator disrupted the vessels in any way. If the vessel was disrupted, it was recorded as a positive finding and photographed (Fig. 2).

\section{RESULTS}

Of the 336 incisions made into the $4^{\text {th }}, 5^{\text {th }}$ and $7^{\text {th }}$ ICS of the 56 cadavers evaluated, only 8 (2.4\%) resulted in a vascular compromise of either the posterior intercostal artery or a collateral branch of that vessel within the $4^{\text {th }}$ space. The $5^{\text {th }}$ and $7^{\text {th }}$ space seemed to show the most damage, 13 and 12 severed collateral branches respectively. While it is impossible to say for certain that such a compromise would lead to a complication, given that the subjects are cadavers, it seems likely that a laceration of the magnitude observed in these 23 subjects would have resulted in substantial bleeding. Sidedness had a significant impact in the $5^{\text {th }}$ and $7^{\text {th }}$ spaces, with the $5^{\text {th }}$ space showing 9/12 collaterals damaged on the left and the $7^{\text {th }}$ space showing $8 / 15$ collaterals damages on the right. The $5^{\text {th }}$ space however showed a decreased likely good of sidedness with 5/8 on the right. Finally, 5 of the 6 of the incisions that resulted in laceration of the posterior intercostal artery or collateral branch were in subjects over the age of 70 (Figs. 3, 4, Table 1).

\section{DISCUSSION}

Complications related to thoracentesis are rare given that the procedure only involves the insertion of a needle into the intercostal space, however, when the procedure involves the insertion of a thoroscope 
Table 1. Percentage of severed posterior intercostal arteries

\begin{tabular}{lcccc}
\hline Intercostal space & Right cut & Left cut & Incidence & Per cent cut \\
\hline 4 & 5 & 3 & $8 / 33$ & $24.24 \%$ \\
5 & 9 & 3 & $12 / 33$ & $36.36 \%$ \\
7 & 8 & 5 & $13 / 33$ & $39.39 \%$ \\
\hline
\end{tabular}

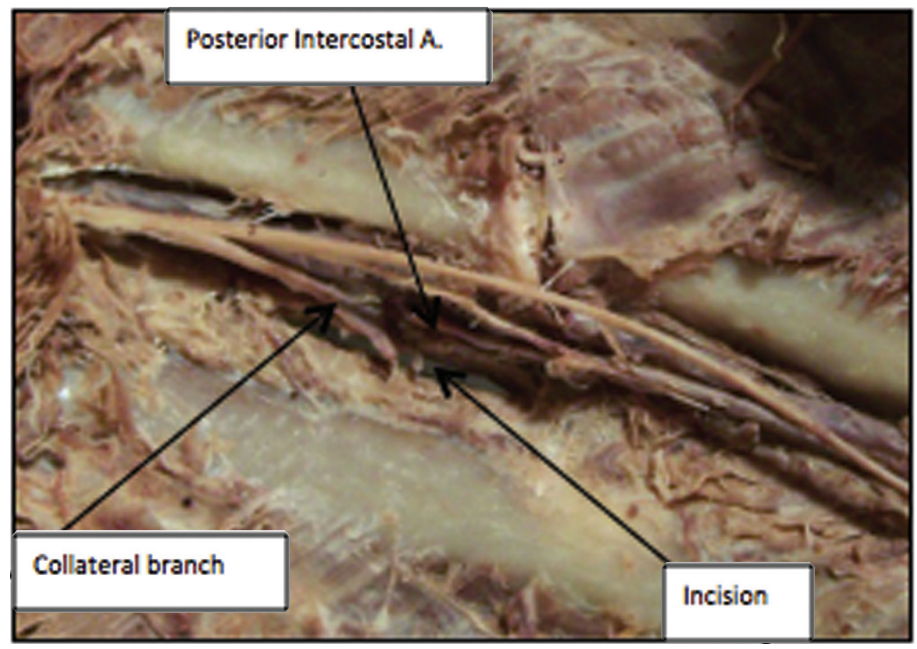

Figure 5. Example of an incision that lacerated either the collateral branch of the $4^{\text {th }}$ intercostal space $(8 / 336 ; 2.4 \%)$.

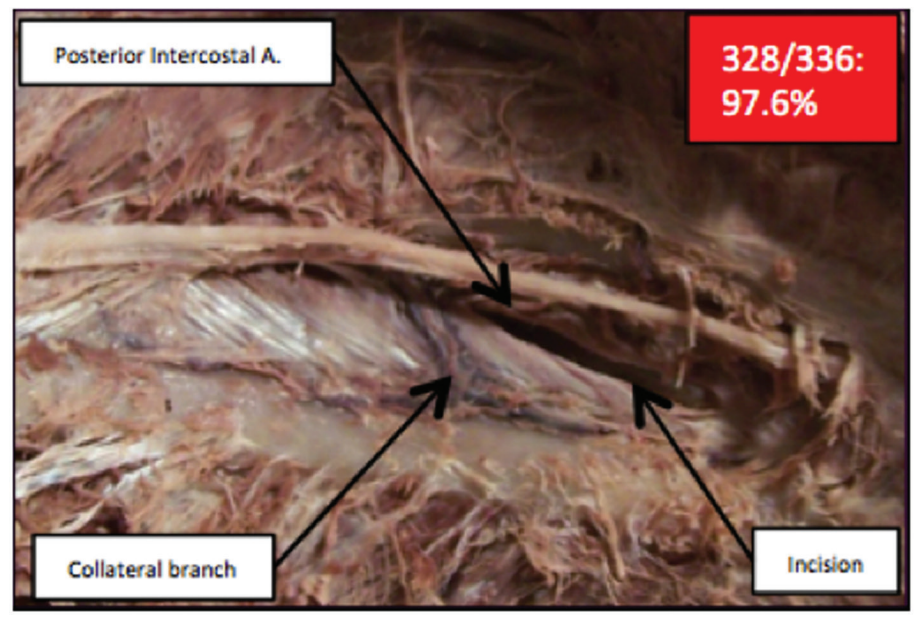

Figure 6. Example of an incision that did not lacerate either the posterior intercostal artery or the collateral branch in the $4^{\text {th }}$ intercostal space (328/336; 97.6\%).

or chest tube that necessitates an incision, the incidence of complication increases. There are several studies that report a wide range of incidences of complications that arise from thoroscopic procedures. A couple of examples include the work of Kransa et al. [8] who report and incidence of $6.5 \%$ among 36 patients, whereas Kaiser and Bavaria [7] report and incidence of complications of $10 \%$ among 200 patients. The current study determined an incidence that would have likely resulted in complications due to the $4^{\text {th }}$ ICS in living patients of $2.4 \%$ among 336 incisions (Fig. 5). This suggests that one of the surgical safe-zone ( $4^{\text {th }}$ ICS) determined by Shurtleff and Olinger [10] may, in fact, be worth factoring into recommended incision sites for thoroscopic procedures since the vessels have a lower risk of damage in this parrticular ICS (Fig. 6). Furthermore, the $4^{\text {th }}$ ICS, $120 \mathrm{~mm}$ from the midline should be the preferentially used, 
when appropriate, for thoroscopic procedures. This is especially useful for gaseous substances due to the higher location on the thoracic cage.

Given that 3 of the vascular compromises from incisions occurred on the left side and 5 occurred on the right side, it seems sidedness may not play a part in being able to predict a safe incision site for a thoracic procedure in the $4^{\text {th }}$ ICS. Furthermore, a surgeon performing a procedure like this will not be relegated to a specific side based on the trauma or disease state for which they are performing the procedure in the first place.

\section{CONCLUSIONS}

Incisions of $2 \mathrm{~cm}$ made though the $4^{\text {th }}$ ICSs $120 \mathrm{~mm}$ from the midline that replicate an incision that would be made for the insertion of a chest tube or thoroscope, resulted in fewer vascular compromises than the incidence of complications reported in the literature.

\section{ACKNOWLEDGEMENTS}

The authors would like to thank the donors without whom none of this research could be accomplished. A special thanks to the institutes in which the data collection came from.

\section{REFERENCES}

1. Carney M, Ravin CE (1979) Intercostal artery laceration during thorocentesis: increased risk in elderly patients. Chest, 75: 520-522.

2. Da Rocha PR, Vengjer A, Blanco A, De Carvalho PT, Dias Mongon ML, Medeiros Fernandes GJ (2002) Size of the collateral artery in adults: anatomical considerations in relation to thorocentesis and throscopy. Surg Radiol Anat, 24: 23-24.

3. Davidson PT (1970) Massive hemothorax caused by bleeding from an intercostal artery. J lowa Med Soc, 60: 389-392.

4. Flores RM, Park B, Rusch VW (2005) Video-assisted thoroscopic surgery. ACS Surg, 4: 1-22.

5. Imperatori A, Rotolo N, Gatti M, Nardecchia E, De Monte L, Conti V, Dominioni L (2008) Peri-operative complications of video-assissted thoroscopic surgery (VATS). Int J Surg, 6: S78-S81.

6. Kaiser LR (1994) Video-assisted thoracic surgery. Ann Surg, 220: 722-733.

7. Kaiser LR, Bavaria JE (1993) Complications of thoroscopy. Ann Thorac Surg, 56: 796-798

8. Kransa MJ, White CS, Aisner SC, Templeton PA, McLaughlin JS (1995) The role of thoroscopy in the diagnosis of interstitial lung disease. Ann Thoac Surg, 59: 348-351

9. Pezzella AT, Adebonojo AS, Hooker SG, Mabogunje AO, Conlan AA (2000) Complications of general thoracic surgery. Curr Probl Surg, 37: 826-827.

10. Shurtleff $E$, Olinger $A B$ (2012) Posterior intercostal artery tortuosity and collateral branch points: a cadaveric study. Folia Morphol, 71: 245-251.

11. Thomsen TW, De La Pena J, Setnik GS (2006) Videos in clinical medicine: thoracentesis. N Engl J Med, 355: e16.

12. Yoneyama H, Masahisa A, Temaru R, Ishizaka S, Minami $S$ (2010) Evaluation of risk of intercostal artery laceration during throcentesis in elderly patients by using 3D-CT angiography. Int Med, 49: 289-292. 